\title{
LOS MEDIOS DE COMUNICACIÓN EN LA CONSTRUCCIÓN DE LA CULTURA POLÍTICA DEMOCRÁTICA EN MÉXICO
}

\section{Jacqueline Peschard*}

Fecha de recepción: marzo 2000

Fecha de aceptación y versión final: abril 2000

Resumen: El texto ofrece un balance del comportamiento de los medios de comunicación durante la época de la hegemonía del PRI en México, poniendo énfasis en la «unilateralidad informativa» que caracterizó a la cobertura de las campañas políticas en radio y televisión

Para atender a esta disparidad informativa, desde 1994, el Instituto Federal Electoral ha realizado monitoreos de los principales noticieros en medios electrónicos durante las campañas electorales, y desde entonces la información que sobre los eventos de campaña ofrecen los medios en su conjunto ha sido más equilibrada, pues al menos los tres principales contendientes han obtenido un espacio relativamente equitativo. No obstante, al descender a nivel de los diferentes estados de la república mexicana, puede apreciarse que en 1997 y durante el primer mes de campaña del 2000, algunas estaciones de radio y canales de televisión siguen presentando sesgos a favor de alguno de los partidos políticos.

Palabras clave: unilateralidad informativa, monitoreo, sesgos en la cobertura, cobertura de campañas, competencia por la audiencia, circunscripciones electorales, valoración de las notas informativas.

Abstract: During the long period of political hegemony of the PRI in Mexico, the information about electoral campaigns reported by the mass media was clearly biased against opposition parties because the PRI received over $80 \%$ of the time given to the parties. From 1994 on, the Federal Electoral Institute has been monitoring the main newsreels on radio and television during electoral campaigns and has found that as a whole, the transmission of the electoral activities of the three main political parties has been balanced. However, when analyzing newsreels in the different states, the bias is still present, but in 1997 it favoured only the PRI, and during the first month of the Presidential campaign of 2000 it favoured the three main parties. This shows that the media have become pluralistic.

Key words: informative unilaterality, monitoring, campaing coverage, canpaing audience, electoral district, news assessment

\section{INTRODUCCIÓN}

En el contexto de lo que Norbert Lechner (1996) llamó las megatendencias mundiales de los años noventa, las instituciones y procesos políticos en México han cambiado notablemente. Las elecciones han dejado de ser rituales que servían a una élite política para sancionar su permanencia en el poder, para convertirse en lo que deben ser en un régimen democrático; el mecanismo para que la sociedad decida quién la gobierne y represente. Con un Instituto Federal Electoral plenamente autónomo, así como con órganos electorales estatales también autonomizados y tribunales electorales estatales y federal con amplias facultades jurisdiccionales, las elecciones son ahora procesos limpios transparentes, organizados imparcialmente y confiables. Además, desde la reforma electoral de 1996 en que se determinaron reglas equitativas de finan- ciamiento de los partidos políticos, así como de acceso a tiempos en radio y televisión, las elecciones mexicanas han devenido competitivas y equitativas.

Esta democratización electoral ha tenido repercusiones sobre el sistema de partidos y el propio sistema político, ya que ha eliminado el monopolio priísta, pues hoy más de $50 \%$ de la población del país que habita los distintos municipios y 11 entidades federativas están gobernadas por un partido diferente al PRI. Aunado a lo anterior, la Cámara de Diputados no cuenta ahora con mayoría absoluta del partido en el gobierno, y el espectro político se ha pluralizado, en la medida que ningún partido se reclama representante del conjunto de los mexicanos y existen canales abiertos

* Consejera Electoral del Consejo General del Instituto Federal Electoral de México. $\square$ peschard@ife.org.mx 
para la formación de nuevos partidos políticos, así como de nuevas agrupaciones políticas nacionales.

En efecto, la arena política se ha pluralizado no sólo porque hoy existen 11 partidos políticos y 41 agrupaciones políticas nacionales registrados, sino porque hay condiciones equitativas de competencia que permiten que ellos se disputen abiertamente los distintos cargos de elección popular.

Las coordenadas tradicionales del sistema político también han cambiado ya que a pesar de que el Presidente de la República sigue siendo la cabeza de la estructura de poder, sus márgenes de acción se han acotado como consecuencia de las propias reformas legales que se han promulgado para impulsar las reformas institucionales.

No obstante que estos cambios han generado modificaciones en el comportamiento de actores sociales y políticos, y de la sociedad misma, a fin de que los cambios se asienten y consoliden como un ingrediente normal y cotidiano de la vida política es necesario que se constituyan en prácticas sociales reconocidas. Para decirlo de otra manera, se requiere que las reglas que animan dichos cambios sean introyectadas por las élites al igual que por la población y puedan, entonces, normar sus conductas de manera regular y permanente.

A manera de ilustración, sondeos de opinión señalan que el IFE es una institución confiable a los ojos de los ciudadanos 1. Sin embargo, eso no se traduce inmediatamente en la convicción extendida de que el Presidente ya no interviene en el nombramiento del sucesor. Los cambios en las instituciones no borran drásticamente concepciones y desconfianzas fuertemente arraigadas, de ahí que sea necesario que se sucedan varios procesos electorales transparentes y confiables para modificar efectivamente percepciones que aún subsisten.

En la construcción de una nueva cultura política democrática que solamente puede fincarse en la existencia de instituciones diseñadas con patrones democráticos, el papel de los medios de comunicación es fundamental por el alcance que tienen (recordemos que hoy la televisión mexicana llega al 95\% del territorio nacional) y consecuentemente por la influencia social que ejercen. Por su alcance y penetración, son agentes de socialización básicos al transmitir valores y referentes colectivos que van orientando aspiraciones y conformando identidades y costumbres. Los medios de comunicación pueden contribuir al despliegue de una cultura democrática si ofrecen información amplia y bien documentada, capaz de alentar una participación política más consciente.

El propósito de este trabajo es analizar el comportamiento de los noticieros de radio y televisión durante las campañas electorales de las últimas dos elecciones federales y lo que va de la actual campaña presidencial. Se trata de ver cómo ha evolucionado la manera como los medios electrónicos informan sobre las campañas políticas en una época en que los comicios mexicanos se han convertido en eventos celosamente vigilados 2 .

\section{POLÍTICA Y MEDIOS DE COMUNICACIÓN EN MÉXICO}

Durante la larga época de la hegemonía priísta, la relación entre medios y política estuvo determinada por la complicidad entre el gobierno y los dueños de los medios, o concesionarios, en el marco de normas siempre rezagadas (la ley de imprenta se remonta a 1917 y la de radio y televisión a 1969, antes de la revolución informática). Los medios electrónicos dependen de que el gobierno les otorgue y extienda las concesiones para el uso del espacio aéreo, pero gozan de prebendas tales como exención de impuestos, a cambio de un pago en especie del $12.5 \%$ del tiempo de transmisión para la difusión de campañas de educación o de servicio a la sociedad por parte de los organismos públicos. Lejos de ser interlocutores o contrapesos del poder como lo son en sociedades democráticas en México los medios de comunicación eran verdaderas comparsas del gobierno.

El oficialismo informativo de los medios era ampliamente reconocido, al punto que particularmente a la televisión privada se le denominaba el cuarto sector, para ubicarla como una más de las instancias corporativas que integran al PRI (Arredondo, 1991: 143).

En esa época, la cobertura de las campañas electorales en radio y televisión estuvo caracterizada por la unilateralidad informativa, pues los noticieros se centraban en reportar los mítines, concentraciones y discursos del candidato oficial a la Presidencia y era muy escaso, cuando no ausente, lo que se informaba sobre opciones diferentes. Eran medios paternalistas, cerrados a opiniones diferentes, que recreaban la falta de competencia política; su papel dentro de las campañas electorales era limitado porque los resultados estaban decididos de antemano. Los medios ayudaban al gobierno y a su partido reiterando mensajes e imagen, pues no necesitaban persuadir al auditorio, ni buscar su apoyo electoral.

El favoritismo de los medios para con el partido del gobierno durante las campañas electorales preocupaba poco a la opinión pública existente, quien estando conforme con el estado de cosas, recibía la información parcial como aquélla que naturalmente se generaba en un sistema de hegemonía de un partido.

1988 fue un parteaguas en la historia político-electoral contemporánea de México porque la elección presidencial fue severamente cuestionada, sin que las autoridades electorales pudieran resolver las impugnaciones y probar la legitimidad de los resultados. Fue en esa coyuntura que se generó la protesta por el sesgo con el que los medios electrónicos cubrían las campañas, beneficiando a un solo par-

1. La encuesta nacional publicada por el periódico Reforma, el 21 de febrero de 2000 , señaló que la población otorga al IFE una calificación de 8.2 sobre 10 .

2. En 1994, por primera vez, la ley electoral contempló la presencia de observadores nacionales y visitantes extranjeros. En esa primera ocasión se registraron más de 80 mil observadores nacionales y 943 visitantes extranjeros. 
tido y dejando prácticamente ocultas las actividades de los candidatos de oposición. Todavía ese mismo año, Emilio Azcárraga, el dueño de Televisa, la principal cadena de televisión privada, declaró abiertamente su profesión de fe priísta. En todo caso, las dudas e inconformidades frente a los resultados electorales abarcaron por vez primera a los medios de comunicación.

El análisis que en ese momento se hizo de la cobertura que hicieron los medios escritos y electrónicos de la campaña presidencial muestra la diferencia que entonces existía entre la prensa escrita y la televisión también capitalinas. Aunque en ambos casos el PRI recibió siempre una atención privilegiada, los diferentes periódicos editados en la ciudad de México, le ofrecieron entre el 36.7\% de sus espacios reservados a las campañas en La Jornada, pasando por el $52.8 \%$ en Excélsior y el $73 \%$ en Novedades, hasta el $83 \%$ en el periódico del gobierno, El Nacional (Trejo Delarbre, 1991: 104).

En contraposición, al PAN sólo le dedicaron el 14.4\% en La Jornada y el $5.8 \%$ en El Nacional, es decir, una atención muy escasa y con una menor variación entre uno y otro diario. El espacio que los periódicos otorgaron al Frente Democrático Nacional que postuló a Cuauhtémoc Cárdenas recibió desde el 7.5\% del espacio en El Nacional, hasta el $28.1 \%$ en el Uno más Uno, es decir, la atención fue ligeramente superior a la recibida por el PAN, pero abismal en relación a la otorgada al PRI.

Al comparar el porcentaje de espacios otorgados a los partidos en los periódicos de la ciudad de México, que son los que tienen mayor circulación, con los resultados electorales, puede apreciarse que no hay una asociación entre ellos, más allá del hecho que el PRI es el que obtuvo la más alta votación $(50.7 \%)$ y también la mayor proporción de espacios en la prensa ( $54.8 \%$ en promedio); el Frente Democrático Nacional (FDN) junto con el Partido Mexicano Socialista (PMS) cuyo candidato presidencial declinó a favor de Cuauhtémoc Cárdenas, alcanzaron el $31.06 \%$ de los votos y un $24.4 \%$ de los espacios en los medios impresos; el PAN, por su parte, recibió el 16.8\% de los votos con sólo $12.3 \%$ de los espacios noticiosos (Trejo Delarbre, 1991: 127).

De lo anterior, si bien no se puede desprender una relación causal entre presencia en los medios y apoyo electoral, sí puede apreciarse cierta sensibilidad de los periódicos hacia una elección más competida.

Esta situación contrasta con la manera como los principales noticieros de televisión cubrieron la campaña presidencial de 1988, favoreciendo notoriamente al PRI. El trabajo de Pablo Arredondo (1991: 156-157) reveló que el principal noticiero de Televisa reservaba el $64 \%$ de las noticias electorales a cubrir la campaña priísta, mientras el principal noticiero de la televisión estatal le otorgaba el $83 \%$.

Si comparamos esa cobertura con los resultados electorales, que con todo y el cuestionamiento significaron la caída más drástica en la votación prísta (de 17 puntos porcentuales respecto de la elección presidencial previa), se puede afirmar que el comportamiento de los medios masivos, particularmente la televisión, no fue determinante para definir las preferencias electorales. La existencia de una oferta opositora, emanada de las propias raíces del sistema político y con posibilidades de disputarle al PRI la presidencia, alimentó el voto útil, junto con el de protesta, rebasando los marcos todavía muy tradicionales y autoritarios de la comunicación política en México.

A partir de entonces, poder vigilar el comportamiento de los medios de comunicación devino una exigencia de los partidos de oposición que se reflejaría en las posteriores negociaciones para las reformas electorales.

A lo largo de todo el decenio de los noventa el peso de los medios de comunicación en la vida política del país creció explosivamente, al punto que hoy ocupan el centro del espectro electoral, desplazando incluso a los propios partidos políticos. Y es que las estructuras de los partidos no pueden competir con la penetración de la radio y la televisión, lo cual permite que los candidatos entren rápida y extensamente en contacto con el electorado sin necesidad de que intervengan sus aparatos partidarios.

La influencia de los medios de comunicación en la política es $\tan$ significativa que hoy se reconoce que hay una supeditación del quehacer político al imperio de los medios, pues éstos imponen en primer término sus formatos, y en segundo término la definición misma de las agendas de campaña (Trejo Delarbre, 1999: 152). De ahí que lo que ahora se destaque en las campañas sean las imágenes más que las ideas, y la capacidad del candidato para comunicar en frases de 20 segundos, sacrificando contenidos sustanciales de la oferta política. La televisión en particular es un vehículo ideal para propagar cuerpos generales de ideas, pero no para explicar detalles o matices de una propuesta política programática.

La preponderancia de la comunicación audiovisual está provocando el empobrecimiento del discurso político y del contenido mismo de los mensajes. Además, como los partidos políticos y los candidatos han ido abandonando los eventos de campaña cara a cara en favor de los promocionales radiofónicos y televisivos, su relación con el electorado está necesariamente siendo mediada por las empresas de comunicación que tienen antes que nada intereses comerciales.

Los políticos profesionales han asumido la lógica de los medios masivos casi como una fatalidad, de suerte que cada vez más sus argumentos políticos se ciñen a los esquemas y reducidos espacios de los medios electrónicos, con lo cual pierden densidad y riqueza, afectando sus líneas de comunicación con la ciudadanía.

En la actualidad, los candidatos a los principales cargos de elección se lanzan a los brazos de los especialistas en el "marketing político" pues están convencidos que un minuto en televisión propicia más votos que un recorrido por varias zonas de una ciudad. Esta supeditación de la política a los medios ha llevado a que éstos sean más que difusores de los temas de las agendas de los partidos, auténticos forjadores de las agendas del debate público.

Lo que los ciudadanos registran de los discursos políticos es lo que los medios difunden, lo que con frecuencia tiene poco que ver con el contenido mismo del discurso y más 
con la pregunta específica que el reportero hace al final del evento. Esto lleva a la confusión a que se ha referido Felipe González, el ex-presidente del gobierno español, pues comúnmente se toma a "la opinión publicada como si fuera la opinión pública" (1999).

A la par que los medios de comunicación han ido invadiendo el espacio político, los partidos y los políticos profesionales han ido perdiendo prestigio, en buena medida por la propia penetración de los medios, que cada vez más, sacan a la luz pública los manejos indebidos de funcionarios gubernamentales y representantes políticos. Sabemos bien que no es que en la actualidad los políticos se hayan convertido repentinamente en corruptos, sino que ahora hay quienes en todo el mundo obtienen ganancias al difundir tales irregularidades, pues son noticias que elevan las ventas de los medios.

En suma, los medios condicionan hoy la comunicación política pero a la vez sirven de contrapeso frente al poder, cumpliendo una función de contraloría, de vigilancia crítica del poder. El problema es que ese contrapeso que ejercen los medios poco tiene que ver con el interés general de la sociedad.

Con estas reflexiones en mente, la pregunta que se antoja pertinente es qué tanto los cambios que se han dado en las reglas y los actores políticos en México han propiciado transformaciones en la manera como los medios informan sobre la política, o dicho de otra manera, qué tanto se han sintonizado con los nuevos datos (pluralidad, competencia) que moldean actualmente a la vida político-electoral en nuestro país.

La experiencia del proceso electoral de 1988 llevó a los partidos políticos a reconocer que los espacios informativos eran territorios de disputa política, y que por ello mismo debían abrirse a la competencia política y a la pluralidad. Ante la falta de reglas para normar la cobertura de las campañas electorales por parte de los medios de comunicación electrónica en 1994, la autoridad electoral dispuso la realización de un monitoreo de noticieros de radio y televisión del Distrito Federal, en el entendido de que buen número de ellos tienen cobertura nacional. Esta medida de control del IFE sobre los noticieros en medios electrónicos fue trasladada al cuerpo del código electoral en noviembre de 1996. De tal suerte, en 1997 y ahora en las elecciones del 2000, el IFE ha contratado monitoreos muestrales de radio y televisión que abarcan a todos los estados del país.

La manera como ha ido evolucionando la cobertura de las campañas electorales por parte de los medios masivos de comunicación es un reflejo de los cambios que han experimentado instituciones, actores y procesos políticos. La comparación de los resultados de los monitoreos de los noticieros durante las campañas electorales de 1994 y 1997 y el primer mes de la de este año muestran como la política y los medios en México han cambiado, pero no siempre en la dirección deseada. Muestran también que a medida que se ha incrementado la competencia política en los distintos estados del país el comportamiento de los medios en la esfera local se ha diversificado como expresión del impacto de lo local en el ámbito político

\section{EVOLUCIÓN DE LA COBERTURA DE LAS CAMPAÑAS ELECTORALES EN RADIO Y TELEVISIÓN}

Como ya señalamos más arriba, en 1988 por primera vez en un proceso electoral los medios de comunicación fueron protagonistas de la contienda, ya que anteriormente eran meros testigos mudos o ciegos de las campañas políticas (Trejo Delarbre, 1991: 42).

Dos reformas electorales mediaron entre aquella elección presidencial y la subsecuente de 1994, pero éstas se concentraron en buscar fórmulas para constituir una autoridad confiable a los ojos de los partidos políticos, así como un padrón electoral y un esquema de organización de los comicios que pudieran ser vigilados puntualmente en cada una de sus fases por los distintos partidos políticos. Fueron reformas encaminadas básicamente a introducir candados de seguridad a lo largo de todo el proceso electoral.

Para la elección inmediatamente posterior a 1988, Raúl Trejo Delarbre volvió a hacer un seguimiento de la cobertura en prensa del Distrito Federal. Los resultados arrojados mostraron, al igual que tres años antes, el tratamiento diferenciado hacia los partidos políticos de periódico a periódico; la novedad fue que esa diferencia se moderó, particularmente en El Nacional -periódico del gobierno-y Novedades que ya sólo otorgaron al PRI el 50\% y 55\% de sus espacios de campaña electoral. La otra novedad fue el incremento generalizado en todos los periódicos para cubrir la campaña del PAN -que subió al nivel de $20 \%$ de los espacios-y la del PRD, que subió al rango de $25 \%$ de los mismos (Trejo Delarbre, 1999: 314).

El proceso electoral de 1994 arrancó con el evento traumático del levantamiento armado en Chiapas, lo cual llevó al gobierno y los actores políticos a firmar un Acuerdo por la Paz, la Democracia y la Justicia ${ }^{3}$, mediante el cual se harían ajustes a las normas electorales y se adoptarían acuerdos para reforzar los controles de la imparcialidad de la autoridad electoral. De tal suerte, el Consejo General del IFE aprobó la realización de un monitoreo de noticieros de radio y televisión que abarcó a estaciones y canales de cobertura nacional, a partir del documento acordado por los partidos políticos sobre los lineamientos generales que deberían guiar el comportamiento de los noticieros en medios electrónicos 4 .

Dicho monitoreo dio cuenta de que el abismo preferencial del que había gozado el PRI en 1988 se había desvanecido quedando a sólo 10 puntos porcentuales de diferencia con relación a la cobertura de las campañas de su más cercano seguidor, el PRD. Aunque la ventaja del PRI en la cobertura en radio fue levemente superior $(35 \%)$ a la registrada por la televisión (30.8\%), ambos medios favorecieron al partido del gobierno en proporciones semejantes (cuadros 1,2 y 3 ).

3. 27 de enero de 1994 .

4. Este documento era más que imperativo, indicativo para el comportamiento de los medios. Véase, Becerra, Ricardo (1995): “Los medios electrónicos y las elecciones de 1994”. En Villanueva, Ernesto (coord.): Derecho y ética de la información. México: Media Comunicación. 
Cuad ro 1.- Distribución de la cobertura nacional en radio (Porcentaje de los tiempos de transmisión)

\begin{tabular}{|l|c|c|c|} 
& 1994 & 1997 & 2000 \\
\hline PAN/AC* & $21.70 \%$ & $26.73 \%$ & $28.00 \%$ \\
\hline PRI & $35.00 \%$ & $29.50 \%$ & $31.00 \%$ \\
\hline PRD/AM* & $26.10 \%$ & $27.64 \%$ & $22.80 \%$ \\
\hline OTRO & $17.20 \%$ & $16.13 \%$ & $18.20 \%$ \\
\hline
\end{tabular}

$$
\text { Fuente: Monitoreo del IFE 1994, 1997, 2000 }
$$

*En la elección del 2000 , el PAN encabeza una coalición electoral con e Partido Verde Ecologis ta de México, denominada Alianza por el Cambio (AC) El partido de la Revolución Democrática encabeza también una coalición electoral que agnupa a cuatro partidos más y q ue se denomina Alianza por México (AM)

Cuadro 2.- Distribución de la cobertura nacional en televisión (Porcentaje de los tiempos de transm isión)

\begin{tabular}{|l|c|c|c|}
\hline & 1994 & 1997 & 2000 \\
\hline PAN/AC & $16.30 \%$ & $23.94 \%$ & $29.00 \%$ \\
\hline PRI & $30.80 \%$ & $24.08 \%$ & $31.10 \%$ \\
\hline PRD/AM & $19.50 \%$ & $24.83 \%$ & $24.20 \%$ \\
\hline OTROS & $33.40 \%$ & $27.15 \%$ & $15.70 \%$ \\
\hline
\end{tabular}

Fuente: Monitoreo del IFE 1994, 1997, 2000

Cuadro 3.- Distribución de la cobertura nacional en ambos medios (Porcentaje de los tiempos de transmisión)

\begin{tabular}{|l|c|c|c|} 
& 1994 & 1997 & 2000 \\
\hline PAN/AC & $19.70 \%$ & $22.43 \%$ & $27.99 \%$ \\
\hline PRI & $33.40 \%$ & $28.62 \%$ & $31.12 \%$ \\
\hline PRD/AM & $23.70 \%$ & $27.18 \%$ & $23.28 \%$ \\
\hline OTROS & $23.20 \%$ & $21.77 \%$ & $17.61 \%$ \\
\hline
\end{tabular}

Fuente: Moni toreo del IFE 1994, 1997, 2000

Para 1997, el monitoreo, que ya para entonces era un mandato de ley, mostró su eficacia, ya que la diferencia en los porcentajes de cobertura de las tres principales campañas políticas prácticamente desapareció en ambos medios de comunicación. Para la elección presidencial del 2000 el equilibrio en el tratamiento de los noticieros entre las tres principales fuerzas políticas se ha mantenido hasta el momento (cuadros 1,2 y 3 ).

$\mathrm{Al}$ hacer un análisis comparado de las tres elecciones reportadas, a nivel desagregado de noticieros en particular, puede apreciarse que mientras en 1994 cuatro de los cinco noticieros de radio seleccionados favorecieron al PRI con el doble del tiempo que le otorgaron a los otros dos principales contendientes, en la elección intermedia de 1997, los cinco noticieros reservaron espacios equilibrados para las tres principales fuerzas políticas y lo mismo volvió a ocurrir en lo que va de la campaña actual del 2000. Los noticieros de radio que tienen cobertura nacional y que se transmiten desde el Distrito Federal han asumido un comportamiento equitativo frente a las campañas electorales y ello mismo les ha retribuido un prestigio como informadores profesionales, lo cual es hoy un activo que deben cuidar si desean mantener el "rating" que han alcanzado (cuadro 4).

Cabe señalar que si bien la preferencia de los tres principales partidos y coaliciones en los noticiarios se han emparejado, existe una brecha en cuanto al tiempo que se asigna a reportar las campañas de los partidos con menor fuerza electoral. Dicho de otra manera, desde la perspectiva de la
Cuadro 4. Distribución de la cobertura de noticieros de radio seleccionados. (Tiem pos absolutos de transm isión)

\begin{tabular}{|c|c|c|c|}
\hline & \multicolumn{3}{|c|}{ Monitor } \\
\hline & 1994 & 1997 & 2000 \\
\hline $\mathrm{PAN} / \mathrm{AC}$ & $1: 38: 07$ & $8: 00: 53$ & $0: 19: 20$ \\
\hline PRI & $3: 06: 07$ & $8: 11: 25$ & $0: 05: 56$ \\
\hline $\mathrm{PRD} / \mathrm{AM}$ & $1: 25: 29$ & $9: 16: 22$ & $0: 07: 40$ \\
\hline Otros & $0: 24: 06$ & $2: 59: 21$ & $0: 10: 25$ \\
\hline Total & $6: 33: 49$ & $28: 28: 01$ & $0: 43: 21$ \\
\hline \multicolumn{4}{|c|}{ Linea directa/Linea directa/Ruiz Healey } \\
\hline PAN/AC & $0: 53: 38$ & $4: 01: 25$ & $1: 14: 58$ \\
\hline PRI & $0: 41: 57$ & $4: 33: 08$ & $1: 07: 14$ \\
\hline $\mathrm{PRD} / \mathrm{AM}$ & $1: 05: 13$ & $4: 39: 59$ & $1: 22: 14$ \\
\hline Otros & $0: 10: 24$ & $1: 26: 10$ & $0: 26: 28$ \\
\hline Total & $2: 51: 12$ & $14: 40: 42$ & $4: 10: 54$ \\
\hline \multicolumn{4}{|c|}{ In formativo panorama/Panorama/Panorama detrás de noticia } \\
\hline $\mathrm{PAN} / \mathrm{AC}$ & $2: 25: 01$ & $3: 36: 08$ & $0: 56: 42$ \\
\hline PRI & $5: 05: 29$ & $3: 33: 37$ & $1: 08: 08$ \\
\hline $\mathrm{PRD} / \mathrm{AM}$ & $2: 36: 48$ & $3: 53: 27$ & $0: 30: 36$ \\
\hline Otros & $2: 21: 47$ & $2: 04: 17$ & $0: 37: 47$ \\
\hline Total & $12: 29: 05$ & $13: 07: 29$ & $3: 13: 13$ \\
\hline \multicolumn{4}{|c|}{ Para empezar/Para empezar/Imágenes in formativas } \\
\hline PAN/AC & $1: 53: 34$ & $2: 51: 11$ & $1: 27: 22$ \\
\hline PRI & $3: 11: 54$ & 2:42: 10 & $1: 18: 30$ \\
\hline $\mathrm{PRD} / \mathrm{AM}$ & $2: 06: 00$ & $2: 48: 30$ & $1: 50: 42$ \\
\hline Otros & $3: 16: 19$ & $4: 52: 31$ & $1: 55: 04$ \\
\hline Total & $10: 27: 47$ & $13: 14: 22$ & $6: 31: 38$ \\
\hline
\end{tabular}

equidad que persigue el Código Electoral, al mandatar el seguimiento de los noticieros de radio y televisión, existen dos franjas diferenciadas respecto de la atención que otorgan a los tres contendientes más fuertes y el resto de los candidatos y partidos políticos (6 en la elección de 1994, 5 en la de 1997 y 3 en la del 2000)

En suma, la presencia equitativa de los principales contendientes es sin duda uno de los cambios más significativos en los medios, pues un noticiero declaradamente proclive al gobierno ya no tiene posibilidades de competir por audiencia. Más aún, los propios canales del gobierno han entrado a esta lógica competitiva y ello se observa claramente en noticieros específicos de televisión, tales como "Enlace" (cuadro 5).

Todavía en 1994, de siete noticieros de televisión considerados, seis otorgaban al PRI el doble de tiempo que al PAN y al PRD. Solamente "Hechos de la Noche" le dio ligeramente más atención al PAN que al PRI. Para 1997 la situación se había ya emparejado en los siete noticieros, incluido "Enlace" que es del Canal 11 del gobierno, que además ha mantenido dicho comportamiento durante la actual campaña electoral (cuadro 5).

La situación empieza a cambiar cuando volteamos los ojos hacia las distintas regiones del país. Si consideramos las cinco circunscripciones en que el país está dividido para fines electorales podemos observar cómo en 1997, en la tercera, cuarta y quinta circunscripciones, correspondientes a las zonas centro-sur y sureste del país, los noticieros de radio cubrían la campaña del PRI hasta con dos veces más tiempo que la del PAN o el PRD. Sólo en las circunscrip- 
Cuadro 5. Distribución de la cobertu ra de not icie ros de tele visión selecciona dos

(Tiempos absolutos de transmisión)

\begin{tabular}{|c|c|c|c|}
\hline & \multicolumn{3}{|c|}{ Al despertar/ Al despertar/Primero noticias } \\
\hline & 1994 & 1997 & 2000 \\
\hline PAN & $0: 51: 20$ & $1: 11: 54$ & $0: 42: 46$ \\
\hline PRI & $1: 37: 40$ & $1: 25: 50$ & $0: 32: 31$ \\
\hline PRD & $1: 15: 20$ & $1: 14: 30$ & $0: 28: 31$ \\
\hline Otros & $3: 16: 07$ & $1: 51: 31$ & $0: 10: 16$ \\
\hline Total & $7: 00: 27$ & $5: 43: 45$ & $1: 54: 04$ \\
\hline \multicolumn{4}{|c|}{ A primera hora/Hola México/Hechos de la mañana } \\
\hline PAN & $1: 00: 46$ & $1: 44: 17$ & $0: 49: 25$ \\
\hline PRI & $1: 56: 44$ & $1: 53: 35$ & $1: 09: 37$ \\
\hline PRD & $1: 00: 48$ & $2: 07: 22$ & $0: 50: 28$ \\
\hline Otros & $0: 55: 11$ & $1: 33: 49$ & $0: 32: 36$ \\
\hline Total & $4: 53: 29$ & 7:19:03 & $3: 22: 06$ \\
\hline \multicolumn{4}{|c|}{24 horas de la tarde $/ 24$ horas de la tarde/Noticiero $15-16 \mathrm{hrs}$} \\
\hline PAN & $0: 17: 43$ & $0: 42: 03$ & $0: 11: 42$ \\
\hline PRI & 1:01:09 & $0: 33: 33$ & $0: 10: 19$ \\
\hline PRD & $0: 17: 30$ & $0: 32: 51$ & 0:09:00 \\
\hline Otros & $0: 46: 54$ & $0: 43: 26$ & $0: 02: 26$ \\
\hline Total & $2: 23: 16$ & $2: 31: 53$ & $0: 33: 27$ \\
\hline \multicolumn{4}{|c|}{24 horas de la noche $/ 24$ horas de la noche $/$ Noticiero $22: 33 \mathrm{hrs}$} \\
\hline PAN & $0: 19: 49$ & $0: 35: 52$ & $0: 15: 25$ \\
\hline PRI & $0: 47: 27$ & $0: 23: 00$ & $0: 17: 37$ \\
\hline PRD & $0: 26: 43$ & $0: 39: 04$ & $0: 12: 24$ \\
\hline Otros & $1: 27: 00$ & $0: 38: 51$ & $0: 07: 04$ \\
\hline Total & $3: 00: 59$ & $2: 16: 47$ & $0: 52: 30$ \\
\hline \multicolumn{4}{|c|}{ Enlace } \\
\hline PAN & $0: 41: 50$ & $1: 31: 28$ & $0: 13: 13$ \\
\hline PRI & $1: 18: 19$ & $1: 26: 28$ & $0: 13: 41$ \\
\hline PRD & $0: 43: 10$ & $1: 29: 50$ & $0: 12: 18$ \\
\hline Otros & $2: 14: 20$ & $1: 57: 26$ & $0: 08: 28$ \\
\hline Total & $4: 57: 39$ & $6: 25: 12$ & $0: 47: 40$ \\
\hline \multicolumn{4}{|c|}{ Muchas noticias/Muc has noticias/Noticiero $19 \mathrm{hrs}$} \\
\hline PAN & $0: 18: 43$ & $0: 16: 15$ & $0: 02: 49$ \\
\hline PRI & $1: 47: 06$ & $0: 29: 13$ & $0: 04: 02$ \\
\hline PRD & $0: 38: 01$ & $0: 14: 44$ & $0: 01: 20$ \\
\hline Otros & $2: 02: 30$ & $0: 32: 13$ & $0: 02: 30$ \\
\hline Total & $4: 46: 20$ & $1: 32: 25$ & $0: 10: 41$ \\
\hline \multicolumn{4}{|c|}{ Hechos de la noc he } \\
\hline PAN & $1: 22: 55$ & $1: 33: 15$ & $0: 23: 32$ \\
\hline PRI & 1:02:35 & $1: 52: 10$ & $0: 26: 54$ \\
\hline PRD & $0: 53: 29$ & $1: 52: 50$ & $0: 23: 08$ \\
\hline Otros & $1: 28: 45$ & $0: 40: 58$ & $0: 28: 43$ \\
\hline Total & 4:47:44 & $5: 59: 13$ & $1: 42: 17$ \\
\hline
\end{tabular}

ciones del norte del país, los noticieros informaban de manera más equitativa. En el año 2000 coberturas extremas ya solamente se presentan en la quinta circunscripción donde el PRI ha recibido la mitad de todo el espacio otorgado a las campañas electorales (cuadro 6).

El caso de la televisión presenta un comportamiento más equilibrado ya que en 1997 la diferencia a favor del PRI se concentró en la tercera circunscripción donde recibió el $55.9 \%$ del tiempo de cobertura, 30 puntos más que lo otorgado a los otros dos principales partidos políticos. Esta disparidad desapareció en el reporte del monitoreo del primer mes de campaña del 2000, puesto que la atención de los noticieros televisivos en las cinco circunscrip-
Cuadro 6.

Cobertura de noticieros de radio por circunscripción electo ral $(1997-2000)^{5}$

\begin{tabular}{|c|c|c|c|c|c|}
\hline Circunscripción & Año & PAN/AC & PRI & PRD/AM & Otros \\
\hline \multirow{2}{*}{$\begin{array}{c}\text { I } \\
\text { (No roeste) }\end{array}$} & 1997 & $27.79 \%$ & $38.88 \%$ & $20.90 \%$ & $12.42 \%$ \\
\hline & 2000 & $33.55 \%$ & $27.05 \%$ & $32.47 \%$ & $6.93 \%$ \\
\hline \multirow{2}{*}{$\begin{array}{c}\text { II } \\
\text { (Norte) }\end{array}$} & 1997 & $30.03 \%$ & $31.60 \%$ & $16.20 \%$ & $22.18 \%$ \\
\hline & 2000 & $36.51 \%$ & $34.04 \%$ & $15.26 \%$ & $14.19 \%$ \\
\hline \multirow{2}{*}{$\begin{array}{c}\text { III } \\
\text { (Sureste) }\end{array}$} & 1997 & $18.75 \%$ & $43.52 \%$ & $25.24 \%$ & $12.49 \%$ \\
\hline & 2000 & $24.73 \%$ & $29.43 \%$ & $29.56 \%$ & $16.28 \%$ \\
\hline \multirow{2}{*}{$\begin{array}{c}\text { IV } \\
\text { (Centro) }\end{array}$} & 1997 & $21.61 \%$ & $43.86 \%$ & $22.95 \%$ & $11.59 \%$ \\
\hline & 2000 & $26.53 \%$ & $31.35 \%$ & $25.82 \%$ & $16.30 \%$ \\
\hline \multirow{2}{*}{$\begin{array}{c}\mathrm{V} \\
\text { (Centro-Sur) }\end{array}$} & 1997 & $16.61 \%$ & $54.82 \%$ & $22.27 \%$ & $6.30 \%$ \\
\hline & 2000 & $15.49 \%$ & $50.12 \%$ & $29.03 \%$ & $5.36 \%$ \\
\hline
\end{tabular}

ciones dio cuenta de una cobertura semejante en todos los casos (cuadro 7).

Cuadro 7

Cobertura de noticie ros de televisión por circunscripción electoral. (1997-2000)

\begin{tabular}{|c|c|c|c|c|c|}
\hline Circunscripción & Año & $\mathrm{PAN} / \mathrm{AC}$ & PRI & $\mathrm{PRD} / \mathrm{AM}$ & Otros \\
\hline \multirow{2}{*}{$\begin{array}{c} \\
\text { (No roeste) }\end{array}$} & 1997 & $25.38 \%$ & $35.36 \%$ & $19.21 \%$ & $20.05 \%$ \\
\hline & 2000 & $17.03 \%$ & $28.33 \%$ & $37.32 \%$ & $17.32 \%$ \\
\hline \multirow{2}{*}{$\begin{array}{c}\text { II } \\
\text { (Norte) }\end{array}$} & 1997 & $20.99 \%$ & $41.67 \%$ & $11.85 \%$ & $25.49 \%$ \\
\hline & 2000 & $23.80 \%$ & $36.98 \%$ & $15.05 \%$ & $24.16 \%$ \\
\hline \multirow{2}{*}{$\begin{array}{c}\text { III } \\
\text { (Sureste) }\end{array}$} & 1997 & $14.53 \%$ & $55.83 \%$ & $14.30 \%$ & $15.33 \%$ \\
\hline & 2000 & $26.04 \%$ & $27.48 \%$ & $31.01 \%$ & $15.47 \%$ \\
\hline \multirow{2}{*}{$\begin{array}{c}\text { IV } \\
\text { (Centro) }\end{array}$} & 1997 & $27.81 \%$ & $33.46 \%$ & $23.84 \%$ & $14.89 \%$ \\
\hline & 2000 & $28.23 \%$ & $31.26 \%$ & $24.86 \%$ & $15.65 \%$ \\
\hline \multirow{2}{*}{$\begin{array}{c}\mathrm{V} \\
\text { (Centro-Sur) }\end{array}$} & 1997 & $11.07 \%$ & $39.74 \%$ & $34.51 \%$ & $14.68 \%$ \\
\hline & 2000 & $23.41 \%$ & $28.29 \%$ & $34.59 \%$ & $13.71 \%$ \\
\hline
\end{tabular}

La difusión de los resultados del monitoreo ha sido una arma muy eficaz para inhibir comportamientos sesgados en los noticieros de algunas zonas del país, aunque desde luego que la propia competencia política ha contribuido significativamente con esta tarea. De tal suerte, en este año 2000, las estaciones de radio en las tercera y cuarta circunscripciones se han emparejado en el tratamiento otorgado a las campañas de los partidos políticos y ya solamente en la quinta circunscripción se mantiene el tratamiento favorecedor para el PRI (cubre los estados de Michoacán, Guerrero y estado de México) (cuadro 6).

$\mathrm{Al}$ descender en el análisis a nivel de los estados la asimetría en las coberturas noticiosas en 1997 es más palpable, pues en Campeche el PRI absorbió por sí solo el $75 \%$ de los espacios en radio, y en Chiapas, Hidalgo, México y San Luis Potosí, más del 50\%. Por el contrario, para este

5. Las cinco circunscripciones electorales en que está dividido el país abarcan los siguientes estados:

I Circunscripción: Baja California, Baja California Sur, Sonora, Sinaloa, Nayarit, jalisco, Colima y Guanajuato.

II Circunscripción: Chihuahua, Coahuila, Nuevo León, Durango, Tamaulipas, Zacatecas, San Luis Potosí y Aguascalientes.

III Circunscripción: Veracruz, Tabasco, Campeche, Yucatán, Quintana Roo, Oaxaca y Chiapas.

IV Circunscripción: Distrito Federal, Hidalgo, Tlaxcala, Puebla y Morelos.

V Circunscripción: Michoacán, Estado de México y Guerrero. 
año 2000 ha aparecido un dato inédito: las disparidades en las coberturas de radio ya no favorecen a un solo partido, sino a alguno de los tres más importantes, es decir, el sesgo se ha pluralizado. En Baja California Sur y Tlaxcala, Alianza por México que encabeza el PRD recibió durante el primer mes de campaña el $58 \%$ y el $71 \%$ de los tiempos en radio respectivamente. En Durango, Hidalgo y Quintana Roo, el PRI acaparó entre el $54 \%$ y el $58 \%$ de los espacios radiofónicos y Alianza por el Cambio, encabezada por el PAN, recibió el $67 \%$ del tiempo en radio en Guanajuato (cuadro 8).

\section{Cuadro 8}

Estados con coberturas noticiosas más sesgadas (Radio)

\begin{tabular}{|l|c|c|c|c|l|c|c|c|c|}
\hline \multicolumn{5}{|c|}{ Monitoreo radio 1997 } & \multicolumn{3}{c|}{ Monitoree radio 2000 } \\
\hline \multicolumn{1}{|c|}{ ENTIDAD } & PAN/AC & PRI & PRD/AM & Otros & \multicolumn{1}{|c|}{ ENTIDAD } & AC & PRI & AM & Otros \\
\hline Campeche & $3.66 \%$ & $75.69 \%$ & $13.20 \%$ & $7.45 \%$ & $\begin{array}{l}\text { Baja Califomia } \\
\text { Sur }\end{array}$ & $20.11 \%$ & $20.25 \%$ & $58.05 \%$ & $1.59 \%$ \\
\hline Chiapas & $9.90 \%$ & $56.21 \%$ & $22.18 \%$ & $11.71 \%$ & Durango & $18.75 \%$ & $58.55 \%$ & $22.46 \%$ & $0.24 \%$ \\
\hline México & $14.06 \%$ & $67.54 \%$ & $11.39 \%$ & $7.01 \%$ & Uuanajuato & $67.22 \%$ & $10.80 \%$ & $4.71 \%$ & $17.27 \%$ \\
\hline Hidalgo & $11.43 \%$ & $54.75 \%$ & $20.41 \%$ & $13.41 \%$ & Hidalgo & $17.64 \%$ & $54.12 \%$ & $16.62 \%$ & $11.63 \%$ \\
\hline San Luis Potosi & $17.79 \%$ & $57.26 \%$ & $12.77 \%$ & $12.18 \%$ & Quintana Roo & $21.53 \%$ & $58.38 \%$ & $18.77 \%$ & $1.32 \%$ \\
\hline
\end{tabular}

Fuente: Monitoreo del IFE 1997. 2000

Algo muy parecido sucede en el caso de los noticieros televisivos en los estados pues todavía hace apenas tres años en cinco estados del país (Aguascalientes, Chiapas, San Luis Potosí, Tabasco y Yucatán) los noticieros de radio locales otorgaban a la campaña del PRI $60 \%$ o más de sus espacios. Para el año 2000 las televisoras en los estados se diversificaron, ya que en cuatro estados (Coahuila, Durango, Hidalgo y Jalisco) el PRI absorbió $60 \%$ o más de los tiempos noticiosos, mientras que Alianza por México lo hizo en Sonora y Tlaxcala y Alianza por el Cambio en Colima y Guerrero (cuadro 9).

Cuadro 9

\begin{tabular}{|c|c|c|c|c|c|c|c|c|c|}
\hline \multicolumn{5}{|c|}{ Monitoree TV 1997} & & \multicolumn{4}{|c|}{ Monitoreo TV 2000} \\
\hline ENTIDAD & PAN/AC & PRI & PRD/AM & Otros & ENTIDAD & $A C$ & PRI & AM & Otrow \\
\hline Aguascalientes & $14.96 \%$ & $60.59 \%$ & $12.76^{\circ} \%$ & $11.69 \%$ & Coahuila & $24.46 \%$ & $59.50 \%$ & $10.47 \%$ & $5.57 \%$ \\
\hline Chiapas & $1399 \%$ & $59.22 \%$ & $17.17 \%$ & $9.62 \%$ & Colima & $69.18 \%$ & $26.86^{\circ} \%$ & $3.96 \%$ & $0.00 \%$ \\
\hline Nayarit & $10.11 \%$ & $48.77 \%$ & $12.61 \%$ & $28.51 \%$ & Durango & $12.19 \%$ & $64.31 \%$ & $23.50 \%$ & $0.00 \%$ \\
\hline San Luis Potosi & $24.31 \%$ & $60.35 \%$ & $8.07 \%$ & $7.27 \%$ & Guerrero & $64.72 \%$ & $28.04 \%$ & $7.24 \%$ & $0.00 \%$ \\
\hline Tabasco & $16.14 \%$ & $69.32 \%$ & $5.22 \%$ & $9.32 \%$ & Hidalgo & $13.62 \%$ & $61.88 \%$ & $3.83 \%$ & $20.68 \%$ \\
\hline \multirow[t]{4}{*}{ Yucatín } & $12.67 \%$ & $67.12 \%$ & $7.35 \%$ & $12.86 \%$ & \begin{tabular}{|l|l|} 
Jalisco \\
\end{tabular} & $2.91 \%$ & $61.05 \%$ & $0.63^{\circ} \circ$ & $35.41 \%$ \\
\hline & & & & & Sonora & $16.09 \%$ & $13.42 \%$ & $63.32 \%$ & $7.17 \%$ \\
\hline & & & & & \begin{tabular}{|l|l} 
Tabasco \\
\end{tabular} & $14.77 \%$ & $47.41 \%$ & $15.33 \%$ & $22.50 \%$ \\
\hline & & & & & 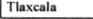 & $28.11 \%$ & $4.11 \%$ & $59.18 \%$ & $8.60 \%$ \\
\hline
\end{tabular}

Vale la pena señalar que estas nuevas disparidades que han aparecido en la elección del 2000 dejaron a una tercera fuerza prácticamente desplazada en los noticieros estatales de televisión, pues en seis uno de los tres principales contendientes sólo llegó a recibir 7\% o menos de los tiempos de cobertura, es decir ocurrió un fenómeno de polarización de los noticieros que los diferencia con nitidez respecto de sus homólogos transmitidos desde la ciudad de México que conceden un tratamiento más equilibrado a los tres principales contendientes.

Estas novedades que se observan en el comportamiento de los medios en los estados reflejan en primer lugar que la dimensión local es determinante en los asuntos políticos, reproduciendo la correlación de fuerzas políticas existente en los estados. De tal suerte, los tres estados donde los noticieros de radio favorecen predominantemente a Alianza por México o a Alianza por el Cambio están gobernados por los partidos que encabezan dichas coaliciones electorales, y lo mismo sucede en el caso de los estados con coberturas extremas en favor del PRI. No obstante, esta relación no se presenta en el caso de los noticieros televisivos, donde aparece más claramente la polarización entre dos fuerzas principales, castigando a un tercer partido (cuadros 8 y 9 ).

Al observar el comportamiento de noticieros individuales en los estados, el partido más beneficiado en los casos de cobertura extrema en el 2000 es el PRI, pues en 7 noticieros de radio recibe más del $53 \%$ del tiempo y éstos se ubican tanto en el Distrito Federal y Toluca (Estado de México) como en Monterrey (Nuevo León), Acapulco (Guerrero), Culiacán (Sinaloa) y San Luis Potosí; para Alianza por el Cambio los casos extremos se localizan en Tijuana (Baja California), Irapuato (Guanajuato) y Nuevo Laredo (Tamaulipas), mientras que para Alianza por México están en La Paz, (Baja California Sur), Los Mochis (Sinaloa), Apizaco (Tlaxcala) y Fresnillo (Zacatecas) (cuadro 11). De los 7 noticieros que privilegian al PRI, 4 se localizan en entidades gobernadas por ese partido. De los 3 que favorecen a la coalición Alianza por el Cambio encabezada por el PAN, 2 se ubican en estados gobernados por dicho partido. De los 4 noticieros que difunden las campañas con un sesgo a favor de Alianza por México, encabezada por el PRD, 3 se localizan en estados gobernados por ese partido. Como puede verse, a este nivel de desagregación vuelve a aparecer como tendencia la relación entre partido en el gobierno y la inclinación privilegiada de los medios a favor de dicha coalición electoral (cuadro 10).

\begin{tabular}{|c|c|c|c|c|c|c|c|}
\hline \multicolumn{8}{|c|}{ RADIO } \\
\hline Entidad & Notidiero & PRI & $A C$ & ANI & PARM & $\mathrm{PCD}$ & Ds \\
\hline Tijuana, BC & \begin{tabular}{|l|}
$\begin{array}{l}\text { Tribuna del } \\
\text { Puveblo }\end{array}$ \\
\end{tabular} & $7.4 \%$ & $661 \%$ & $23.5 \%$ & $1.2^{\circ}$ & $1.2 \%$ & $0.6^{\circ}$ \\
\hline La Paz, BCS & Cobertura & $0.7 \%$ & $8.9 \%$ & $8920^{\circ}$ & $0.4 \%$ & $0.4 \%$ & $0.4 \%$ \\
\hline \begin{tabular}{|l|} 
Mexico, DF \\
\end{tabular} & \begin{tabular}{|l|} 
Antena Radio 1 \\
\end{tabular} & $32 \%$ & $26.4 \%$ & $15 \%$ & $28 \%$ & $1.6 \%$ & $0.6^{\circ} \%$ \\
\hline \begin{tabular}{|l|} 
Irapuato, GTO \\
\end{tabular} & \begin{tabular}{|l|} 
Radio Noticias \\
\end{tabular} & $9.3 \%$ & $67.6 \%$ & $4.7 \%$ & $6.6 \%$ & $10.5 \%$ & $1.2 \%$ \\
\hline \begin{tabular}{|l|} 
Acapullow, GRO \\
\end{tabular} & De Viva $\mathrm{V}_{0 z}$ & 6486 & $11.3 \%$ & $20.0 \%$ & $1.3 \%$ & $1.3 \%$ & $1.3 \%$ \\
\hline \begin{tabular}{|l|} 
Toluca, MEX \\
\end{tabular} & Al Instante & $680 \%$ & $9.5 \%$ & $13.1 \%$ & $0.0 \%$ & $7.5 \%$ & $1.9 \%$ \\
\hline \begin{tabular}{|l} 
Monterrey, NL \\
\end{tabular} & Tribuna Libre & $39.6 \%$ & $5.6 \%$ & $7.1 \%$ & $6.3 \%$ & $19.7 \%$ & $1.8 \%$ \\
\hline \begin{tabular}{|l|} 
Monterrey, NL. \\
\end{tabular} & \begin{tabular}{|l|} 
Enlace 99 \\
\end{tabular} & 36.68 & $10 . \% \%$ & $4 \%$ & $16 . \% \%$ & $11.0 \%$ & $0.2 \%$ \\
\hline \begin{tabular}{|l|} 
Culiacain, SIN \\
\end{tabular} & Este Dia & $63 \%$ & $11.1 \%$ & $21.0 \%$ & $0.3 \%$ & $4.6 \%$ & $0.0 \%$ \\
\hline Los Mochis, SIN & \begin{tabular}{|l|} 
Guardianes \\
Noche
\end{tabular} & $25.1 \%$ & $15.6 \%$ & 9918 & $0.0 \%$ & $0.2 \%$ & $0.0 \%$ \\
\hline \begin{tabular}{|l} 
SLP, SLP \\
\end{tabular} & Al Dia & $602 \%$ & $11.5 \%$ & $3.9 \%$ & $24.0 \%$ & $0.0 \%$ & $0.0 \%$ \\
\hline \begin{tabular}{|l|} 
N. Laredo, TAM \\
\end{tabular} & \begin{tabular}{|l} 
Primera Edición \\
\end{tabular} & $12.9 \%$ & 6876 & $13.1 \%$ & $4.1 \%$ & $1.2 \%$ & $0.0 \%$ \\
\hline Apizasco, TL.AX & \begin{tabular}{|l|l|} 
Enlace \\
Iftornotiva
\end{tabular} & $10.3 \%$ & $3.2 \%$ & $865 \%$ & $0.0 \%$ & $0.0 \%$ & $0.0 \%$ \\
\hline Fresnillo, ZAC & Frente a Frente & $2 . \%$ & $13.3 \%$ & $831 \%$ & $0.9 \%$ & $0.0 \%$ & $0.0 \%$ \\
\hline
\end{tabular}

En el caso de canales de televisión en los estados, de los casos extremos de distribución de los tiempos, 8 favorecen al PRI en Saltillo, Colima, Distrito Federal, Durango, Pachuca, Guadalajara y Villahermosa; 2 dan alta ventaja a Alianza por el Cambio en Chihuahua y Acapulco y 3 más se la dan a Alianza por México en Morelia, Hermosillo y Tlaxcala.

De los 8 noticieros televisivos con sesgos a favor del PRI en la cobertura de las campañas electorales, 5 se ubican en estados gobernados por él. Ninguno de los 2 noticieros que privilegian a Alianza por el Cambio se localizan en entidades gobernadas por el PAN y, de los 3 noticieros con sesgos a favor de Alianza por México sólo 1 se encuentra en un estado gobernado por el PRD. Dicho de 
otra manera, en el caso de la televisión no se recrea la tendencia a que las disparidades en las formas de transmitir los eventos de las campañas tengan relación con los partidos que gobiernan las entidades desde donde transmiten los noticieros (cuadro 11).

Cuadro 11.

\begin{tabular}{|c|c|c|c|c|c|c|c|}
\hline \multicolumn{8}{|c|}{ TELEVISIÓN } \\
\hline Entidad & Noticiero & PRI & $\mathrm{AC}$ & AM & PARM & PCD & DS \\
\hline Saltillo, COAH & A Primera Hora & $393 \%$ & $18.5 \%$ & $9.3 \%$ & $3.7 \%$ & $3.7 \%$ & $5.6 \%$ \\
\hline \begin{tabular}{|l|} 
Colima, COL \\
\end{tabular} & \begin{tabular}{|l|l|l|} 
Al Dia \\
\end{tabular} & $6622 \%$ & $29.4 \%$ & $4.3 \%$ & $0.0 \%$ & $0.0 \%$ & $0.0 \%$ \\
\hline Chih., CHIH & \begin{tabular}{|l|} 
Contacto \\
Nocturno \\
\end{tabular} & $12.5 \%$ & 68.80 & $18.8 \%$ & $0.0 \%$ & $0.0 \%$ & $0.0 \%$ \\
\hline Mexicoo, DF & Hechos del 7 & $55.4 \%$ & $6.0 \%$ & $38.6 \%$ & $0.0 \%$ & $0.0 \%$ & $0.0 \%$ \\
\hline Durango, DGO & Hoy en Durango & $72.6 \%$ & $19.6^{\circ} \%$ & $78 \%$ & $0.0 \%$ & $0.0 \%$ & $0.0 \%$ \\
\hline Acapulco, GRO & \begin{tabular}{|l|} 
Buenos Dias \\
Acapulco \\
\end{tabular} & $14.5 \%$ & 8550 & $0.0 \%$ & $0.0 \%$ & $0.0 \%$ & $0.0 \%$ \\
\hline \begin{tabular}{|l} 
Pachuca, HGO \\
\end{tabular} & \begin{tabular}{|l|} 
Desayuno \\
Noticias
\end{tabular} & $67.6 \%$ & $7.3^{\circ} \%$ & $6.2 \%$ & $0.0 \%$ & $18.9 \%$ & $0.0 \%$ \\
\hline Guad. JAL & $\begin{array}{l}\text { Esta Mañana } \\
\text { Jaliseo }\end{array}$ & $58.90 \%$ & $1.8^{\circ}$ & $0.7 \%$ & $18.0 \%$ & $20.4^{\circ}$ & $0.2 \%$ \\
\hline Guad, JAL & $\begin{array}{l}\text { Buenos Dias57.74 } \\
\text { Guadalajara }\end{array}$ & $49 \%$ & $0.7 \%$ & $35.8 \%$ & $0.0 \%$ & $0.8 \%$ & \\
\hline Morelia, MICH & \begin{tabular}{|l|}
$\begin{array}{l}\text { Noticicero } \\
\text { Michoacano }\end{array}$ \\
\end{tabular} & $11.4 \%$ & $7.6^{\circ} \%$ & $623 \%$ & $15.2^{\circ}$ & $0.0 \%$ & $36^{\circ} 6$ \\
\hline Hemmosillo, SON & $\begin{array}{l}\text { Mesa de } \\
\text { Redarción }\end{array}$ & $12.3 \%$ & $14.9 \%$ & $66.8 \%$ & $1.7 \%$ & $1.3 \%$ & $3.0 \%$ \\
\hline Villaherm.. TAB & Notinueve & $48.54 \%$ & $6.3 \%$ & $2.2{ }^{\circ}$ & $0.0^{\circ} \circ$ & $15.1 \%$ & $27.9 \%$ 。 \\
\hline Tlaxcala, TLAX & Sucesos & $4.1 \%$ & $28.1 \%$ & $39.2 \%$ & $0.0 \%$ & $8.6^{\circ} \mathrm{o}$ & $0.0 \%$ 。 \\
\hline
\end{tabular}

El monitoreo de este año 2000 ha permitido ir más allá de la sola cuantificación de los tiempos otorgados por los noticieros a cada uno de los partidos políticos para analizar si existe alguna valoración en la presentación de la nota informativa. Cabe destacar que del conocimiento del conjunto de notas monitoreadas, la gran mayoría tuvo una valoración neutra (95\% de las de televisión y $86 \%$ de las de radio). La distribución de la pequeña franja que sí fue adjetivada a nivel nacional muestra que las positivas se concentran en el PRI y Alianza por México, mientras que las negativas afectan sobre todo a Alianza por el Cambio (gráfica 1).

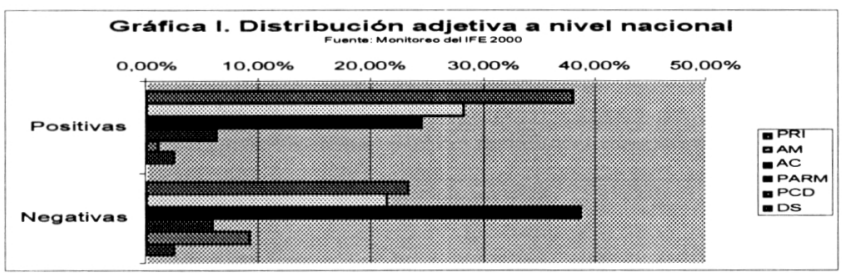

\section{CONSIDERACIONES FINALES}

En suma, la información sobre las campañas políticas en el proceso electoral del 2000 en México se caracteriza por una serie de datos novedosos. Más allá del hecho de que sean las primeras elecciones presidenciales organizadas por una autoridad electoral plenamente autónoma y calificadas por la autoridad jurisdiccional que ahora forma parte del Poder Judicial de la Federación, son elecciones fuertemente competitivas, normadas por un esquema equitativo de financiamiento y por reglas muy firmes de fiscalización de los ingresos y gastos de los partidos políticos, es decir, es una contienda normada por fuertes exigencias de equidad y compromiso entre los contendientes.

La cobertura mediática de las campañas se ha pluralizado, particularmente en la esfera local, ya que los candidatos de todos los partidos encuentran espacios para desplegar sus ofertas, aunque los tres más importantes aca- paran el $83 \%$ de los tiempos y espacios noticiosos. Atrás quedó la época de sujeción de los grandes empresarios de los medios de comunicación a los dictados del gobierno, en buena medida como consecuencia de la expansión de la competencia política.

La omnipresencia de los medios en la política mexicana ha dotado a los concesionarios de una capacidad para chantajear al poder. El intento fallido de reformar la ley de información por parte de un importante grupo de legisladores en 1999 evidenció la resistencia corporativa de los medios de comunicación para que las leyes que regulan su actuación se pongan al día. Sin embargo, este hecho importante ha permitido, además de un cierto contrapeso frente al poder, la conformación de una opinión pública más crítica, con más diversas fuentes de información y, en consecuencia, con mayores exigencias. No obstante, esto es apenas un primer paso en el todavía largo trayecto para que los medios de comunicación asuman su responsabilidad social en tanto fuentes privilegiadas de socialización política en nuestro país.

Los referentes del comportamiento político han cambiado, las percepciones y expectativas de los distintos sectores de la población se han ido redefiniendo en un marco de reconocimiento de la diversidad. Los tiempos electorales son un momento privilegiado para observar y evaluar los cambios que se han ido sucediendo en los medios de comunicación como expresión de las modificaciones que han experimentado instituciones y procesos políticos en el México de los últimos dos lustros, así como sus efectos sobre la conformación de una cultura política democrática en México.

\section{BIBLIOGRAFIA}

ARredondo, Pablo (1991): “Opacidad en la ventana electrónica: el proceso electoral de 1988 en los noticieros televisivos”. En Arredondo, P., Fregoso, G. y R. Trejo Delarbre: Así se calló el sistema. Comunicación elecciones en 1988. México: Universidad de Guadalajara.

BECERRA, Ricardo (1995): "Los medios electrónicos y las elecciones de 1994". En Villanueva, Ernesto (coord.): Derecho y ética de la información. México: Media Comunicación.

GONZÁlEZ, Felipe (1999): La aceptabilidad de la derrota. Ponencia presentada en el Instituto Federal Electoral.

LECHNER, Norbert (1996): "Las transformaciones de la política”. En Revista Mexicana de Sociología, LVIII: 1 (eneromarzo).

Trejo Delarbre, Raúl (1991): "Campaña y elecciones en la prensa de la ciudad de México”. En Arredondo, P., Fregoso, G. y R. Trejo Delarbre: Asi se calló el sistema. Comunicación elecciones en 1988. México: Universidad de Guadalajara.

TREjo Delarbre, Raúl (1991): "El proceso electoral de 1988”. En Arredondo, P., Fregoso, G. y R. Trejo Delarbre: Asi se calló el sistema. Comunicación elecciones en 1988. México: Universidad de Guadalajara.

Trejo Delarbre, Raúl (1999): Medios y política en México. Procesos electorales y cambio social. Tesis de Doctorado en Sociología, F.C.P. y S., UNAM. 